Article

\title{
Removal of Ammonium from Swine Wastewater Using Synthesized Zeolite from Fly Ash
}

\author{
Hui Tang ${ }^{1}$, Xiaoyi $\mathrm{Xu}^{2, *}$, Bin Wang ${ }^{1}$, Chenpei $\mathrm{Lv}^{1}$ and Dezhi Shi ${ }^{1, *(\mathbb{D})}$ \\ 1 Key Laboratory of Three Gorges Reservoir Region's Eco-Environment, Ministry of Education, \\ Chongqing University, Chongqing 400045, China; tangh@cqu.edu.cn (H.T.); wangbin@cqu.edu.cn (B.W.); \\ lvchenpei@tylin.com.cn (C.L.) \\ 2 School of Environmental Science and Engineering, Suzhou University of Science and Technology, \\ Suzhou 215001, China \\ * Correspondence: xuxiaoyi@cqu.edu.cn (X.X.); shidezhi@cqu.edu.cn (D.S.)
}

Received: 14 March 2020; Accepted: 15 April 2020; Published: 22 April 2020

\begin{abstract}
Synthetic zeolites with pretreated fly ash as a raw material were used to remove ammonium from wastewater using a hydrothermal method in this study. Two pretreatment methods of fly ash were used to compare the ammonium removal of zeolites: water-washing and pickling. In addition, the effects of several factors including the time, temperature, $\mathrm{pH}$, adsorbent dosage, coexisting ions and initial concentration were investigated to gain insight into the adsorption rate, behavior and mechanism of synthetic zeolites for ammonium. $\mathrm{N}_{2}$ adsorption/desorption isotherms showed that the synthetic zeolite was a mesoporous material with a higher specific area $\left(13.05 \mathrm{~m}^{2} / \mathrm{g}\right)$ than the values for raw fly ash $\left(0.34 \mathrm{~m}^{2} / \mathrm{g}\right)$. The X-ray diffraction result suggested that the synthetic products mainly belonged to zeolite $\mathrm{P}$ and $\mathrm{Y}$. The adsorption kinetic data fitted well with a pseudo-second-order model. The maximum ammonium adsorption capacity was $32.16 \mathrm{mg} / \mathrm{g}$. The synthetic zeolites were also applied to adsorb the ammonium from real swine wastewater. The ammonium removal efficiencies in raw swine wastewater and effluent from the biochemical unit were $64.34 \%$ and $79.61 \%$, respectively, which indicated that the synthetic zeolites have a good application for real ammonium wastewater.
\end{abstract}

Keywords: fly ash; synthesis; zeolite; ammonium; swine wastewater

\section{Introduction}

Wastewater from industrial pig farms has 20-50 times more ammonium than domestic sewage, as well as differing concentrations of phosphate and metal ions [1]. The high ammonium concentration and complex water quality of swine wastewater might inhibit the activity of nitrifying bacteria used in conventional nitrogen bio-removal processes [2]. Presently, there are several technologies to remove nutrients from swine wastewater, including chemical precipitation, adsorption, constructed wetland, advanced biological treatment, etc. [3,4]. Among these techniques, adsorption was often regarded as a promising method for ammonium removal due to its low cost, stable effect, convenient operation and mild condition [5]. Some adsorbents, such as biochar, palygorskite, and zeolite, have been used to treat swine wastewater [6-8].

Zeolite is a crystalline aluminosilicate mineral that mainly consists of tetrahedral $\mathrm{SiO}_{4}$ and $\mathrm{AlO}_{4}$. Zeolite has been shown to successfully adsorb ammonium from wastewater because of its uniform pores, large surface area, and ion exchange capacity [9]. Due to the high content of $\mathrm{Si}$ and $\mathrm{Al}$, low cost, and advocacy of waste reuse, fly ash, about 780 million tons of which are discharged annually by fire power plants, was a very valuable raw material for the synthesis of zeolite by a conventional hydrothermal processes, which also relieve the environmental pressure of solid wastes [10]. The synthesized zeolite from fly ash (ZFA) has been widely applied to the removal of nutrients from wastewater. The zeolite 
prepared from raw fly ash often has a low adsorption capacity for ammonium, and its application was limited in the field of high concentration wastewater [11]. Therefore, some suitable pretreatments of raw fly ash before a conventional hydrothermal process and optimum synthesis parameters before use are necessary to acquire a higher adsorption capacity for ammonium [12,13].

At present, various pretreatment methods like magnetic separation and salt solution are applied to raw fly ash $[14,15]$. However, there are still some problems in its application to swine wastewater, such as low ammonium adsorption capacity, strict operation conditions, the influence of coexisting ions, and the ammonium concentration limit [16-18]. It is hypothesized that combined pretreatment methods of acid and ultrasound before water-heated alkaline reaction and the optimization of synthesis parameters could improve and overcome these problems. At present, the synthesized zeolite from fly ash has drawn more attention due to the low cost and large production of fly ash. The challenge for researchers is to study a type of synthesized zeolite from fly ash with a higher adsorption capacity for ammonium, and it can treat ammonium wastewater with a higher concentration.

In this study, the synthesized zeolites were prepared from acid-treated fly ash, then the effects of preparation parameters of zeolites for ammonium adsorption were determined, and the adsorbents were characterized to study textural properties. By evaluating the physicochemical properties of the raw materials as well as the pretreatment and synthesis methods for synthetic zeolites, our study focused on the treatment of ammonium-rich wastewater using synthetic products. The adsorption behavior and mechanism were investigated with various adsorption parameters such as $\mathrm{pH}$ value, initial ammonium concentration, temperature, adsorbents dosage and coexisting ions. The application of the synthesized zeolite for adsorption ammonium from real swine wastewater was also evaluated.

\section{Materials and Methods}

\subsection{Materials}

Fly ash used for zeolite synthesis was obtained from a power plant in Henan, China. Ammonium chloride $\left(\mathrm{NH}_{4} \mathrm{Cl}\right)$, Nessler reagent, potassium sodium tartrate, sodium chloride $(\mathrm{NaOH})$, hydrochloric acid $(\mathrm{HCl})$, sodium chloride $(\mathrm{NaCl})$, potassium chloride $(\mathrm{KCl})$, potassium dichromate and all other chemicals were purchased from Chuan Dong Chemical Engineering Co., Ltd. (Chongqing, China). The real swine wastewater was acquired from an intensive pig farm in Chongqing, China. The sample included raw wastewater and effluent from the biochemical unit. Water quality indicators of the fresh samples are shown in Table 1. The swine wastewater sample was passed through a $0.22 \mu \mathrm{m}$ Millipore filter before the adsorption studies.

Table 1. Characteristics of fresh swine wastewater.

\begin{tabular}{cccc}
\hline Parameters & Unit & $\begin{array}{c}\text { Raw } \\
\text { Swine Wastewater }\end{array}$ & $\begin{array}{c}\text { Effluent from the } \\
\text { Biochemical Unit }\end{array}$ \\
\hline $\mathrm{pH}$ & $/$ & 7.84 & 6.32 \\
$\mathrm{NH}_{4}{ }^{+}-\mathrm{N}$ & $\mathrm{mg} / \mathrm{L}$ & 584 & 189 \\
Total nitrogen & $\mathrm{mg} / \mathrm{L}$ & 605 & 199 \\
$\mathrm{PO}_{4}{ }^{3-}-\mathrm{P}$ & $\mathrm{mg} / \mathrm{L}$ & 56 & 50 \\
Total phosphorus & $\mathrm{mg} / \mathrm{L}$ & 269 & 61 \\
Chemical oxygen demand & $\mathrm{mg} / \mathrm{L}$ & 3600 & 256 \\
$\mathrm{Na}$ & $\mathrm{mg} / \mathrm{L}$ & 569 & 332 \\
$\mathrm{~K}$ & $\mathrm{mg} / \mathrm{L}$ & 702 & 437 \\
$\mathrm{Ca}$ & $\mathrm{mg} / \mathrm{L}$ & 310 & 195 \\
$\mathrm{Mg}$ & $\mathrm{mg} / \mathrm{L}$ & 413 & 289 \\
$\mathrm{Zn}$ & $\mathrm{mg} / \mathrm{L}$ & 1.20 & 0.32 \\
$\mathrm{Cu}$ & $\mathrm{mg} / \mathrm{L}$ & 0.30 & 0.16 \\
\hline
\end{tabular}




\subsection{Pretreatment of Fly Ash}

There are two pretreatment methods of raw fly ash: water-washing and pickling. For water-washing, raw fly ash and deionized water were mixed at a $10 \%$ ratio $(\mathrm{w} / \mathrm{v})$. After a $24 \mathrm{~h}$ agitation at $25{ }^{\circ} \mathrm{C}$, the samples were centrifuged to discard the clear supernatant. For pickling, raw fly ash was pretreated by deionized water before acid pretreatment in order to save hydrochloric acid $(\mathrm{HCl})$ usage. Then, the water-washed fly ash and $2 \mathrm{M} \mathrm{HCl}$ were mixed at a ratio of $9 \%(\mathrm{w} / \mathrm{v})$ and stirred for $1 \mathrm{~h}$ at $80^{\circ} \mathrm{C}$. The fly ash pretreated with $\mathrm{HCl}$ was washed several times with deionized water to remove excess chloride. Finally, all of products pretreated above were washed with anhydrous ethanol, dried at $105^{\circ} \mathrm{C}$, ground to pass through a 200-mesh screen, and stored until use.

\subsection{Hydrothermal Zeolite Synthesis}

Zeolites were prepared from fly ash using a hydrothermal synthesis method. After pretreatment, the fly ash samples were mixed with $2 \mathrm{M} \mathrm{NaOH}$ at different liquid-solid ratios (L/S), and then stirred magnetically for $12 \mathrm{~h}$ in a water bath after ultrasound at $30 \mathrm{kHz}$ for $30 \mathrm{~min}$ at $25^{\circ} \mathrm{C}$. Subsequently, the samples acquired were transferred in a series of reaction kettles and reacted for different hour durations in an oven at various temperature $\left(80-200^{\circ} \mathrm{C}\right)$. Finally, the synthesized zeolites were washed with deionized water and anhydrous ethanol to dry and sieved through a 200-mesh sieve before use.

\subsection{Characterization}

X-ray fluorescence (XRF) spectrometry was used for the multielement analysis of the fly ash samples (Philips PW2404, Philips Co. Holland). The tests were performed in triplicate, and their average data were reported. The crystalline phases were identified by $X$-ray diffraction (XRD) using a D8 Advance X-ray diffractometer (Bruker). The scanning electron microscopy (SEM) micrographs of the materials were performed using a Zeiss Merlin Compact (Zeiss, Oberkochen, Germany). The Brunauer-Emmett-Teller (BET) technique was used to measure the specific surface area and pore size of the materials using a Gemini VII 2390p surface area analyzer. The functional groups were determined with a Fourier 20 transform infrared spectrometer (FTIR; IR Pvestige-21, Shimadzu, Japan).

\subsection{Adsorption Experiments}

Ammonium adsorption experiments were conducted to obtain appropriate preparation conditions by the ZFA under different synthesis parameters. Batch experiments were conducted in an array of conical flasks, $100 \mathrm{~mL} 100 \mathrm{mg} / \mathrm{L}$ ammonium solutions were added to $250 \mathrm{~mL}$ Erlenmeyer flasks with $1 \mathrm{~g}$ ZFA, sealed and shaken at a speed of $180 \mathrm{rpm}$ for $2 \mathrm{~h}$ in a mechanical shaker with a $25^{\circ} \mathrm{C}$ water bath. The influence factors of ammonium adsorption were studied with the variation in $\mathrm{pH}(2-9)$, adsorbent dosage (5-60 g/L), and initial ammonium concentration $(20-500 \mathrm{mg} / \mathrm{L})$. Finally, the effect of coexisting ions $\left(\mathrm{Na}^{+}, \mathrm{Ca}^{2+}, \mathrm{K}^{+}, \mathrm{Mg}^{2+}\right)$ on ammonium adsorption was investigated at individual ion concentrations of $10 \mathrm{mM}$.

The ammonium adsorption kinetics were studied within a time range from 30 to $1440 \mathrm{~min}$. The adsorption isotherm tests were analyzed at 288, 298, and $308 \mathrm{~K}$. The ZFA was applied to swine wastewater treatment so as to know the actual ammonium adsorption efficiency. The equilibrium ammonium concentration was measured using Nessler's reagent spectrophotometry, and three replicates were performed in parallel for each set of experiments.

\subsection{Data Analysis}

Differences in the ammonium concentration between the initial and residual solution were used to calculate the equilibrated adsorption capacity. The removal efficiency $(R \%)$ and the adsorption capacities of adsorbents at time $\left(q_{t}, \mathrm{mg} / \mathrm{g}\right)$ and at equilibrium $\left(q_{e}, \mathrm{mg} / \mathrm{g}\right)$ were calculated using the following equations: 


$$
\begin{aligned}
& R=\frac{100\left(C_{0}-C_{t}\right)}{C_{0}} \\
& q_{t}=\frac{\left(C_{0}-C_{t}\right) V}{m} \\
& q_{e}=\frac{\left(C_{0}-C_{e}\right) V}{m}
\end{aligned}
$$

where $q_{e}(\mathrm{mg} / \mathrm{g})$ is the equilibrium absorption capacity of ammonium; $C_{0}, C_{t}$, and $C_{e}(\mathrm{mg} / \mathrm{L})$ are the ammonium concentrations at the start, any time (t), and equilibrium, respectively; $V$ is the total solution volume (L); and $m$ is the mass of the adsorbents $(\mathrm{g})$.

\section{Results and Discussion}

\subsection{Characterization of Materials}

The XRF compositions of fly ash samples obtained by different pretreatment methods are shown in Table 2. Compared with raw fly ash, the contents of $\mathrm{CaO}$ and $\mathrm{Na}_{2} \mathrm{O}$ in fly ash decreased by $5.33 \%$ and $17.81 \%$ after water-washing, respectively. After pickling, $\mathrm{Al}_{2} \mathrm{O}_{3}$ and $\mathrm{SiO}_{2}$ in the fly ash continued to increase, and $\mathrm{Si} / \mathrm{Al}$ decreased, which improves the activity and crystallinity of synthetic zeolite and leads to a greater cation exchange capacity (CEC) of the synthesized zeolites [19]. Some impurities (metal oxides) in fly ash were reduced by at least $30-40 \%$ in the acid pretreatment, and meanwhile the loss of effective ingredients were reduced.

Table 2. Composition and content list of the pretreated fly ash.

\begin{tabular}{cccc}
\hline Components & Raw & Water-Washing & Pickling \\
\hline $\mathrm{SiO}_{2}$ & $58.00 \%$ & $58.17 \%$ & $58.69 \%$ \\
$\mathrm{Al}_{2} \mathrm{O}_{3}$ & $30.00 \%$ & $30.41 \%$ & $38.42 \%$ \\
$\mathrm{Fe}_{2} \mathrm{O}_{3}$ & $4.30 \%$ & $4.31 \%$ & $1.20 \%$ \\
$\mathrm{CaO}$ & $1.50 \%$ & $1.42 \%$ & $0.59 \%$ \\
$\mathrm{MgO}$ & $2.80 \%$ & $2.84 \%$ & $0.49 \%$ \\
$\mathrm{Na} O$ & $3.20 \%$ & $2.63 \%$ & $0.35 \%$ \\
$\mathrm{Impurity}$ & $0.20 \%$ & $0.22 \%$ & $0.26 \%$ \\
$\mathrm{Si} / \mathrm{Al}$ & 1.70 & 1.69 & 1.34 \\
\hline
\end{tabular}

The XRD patterns of the synthesized products are presented in Figure S1. The main products were zeolite $\mathrm{P}$, zeolite $\mathrm{Y}$, and subordinate Faujasite, with zeolite $\mathrm{P}$ exhibiting a high diffraction peak intensity and a sharp peak shape. Hydrothermal synthesis of ZFA at higher concentration of $\mathrm{NaOH}$ results in the conversion of zeolite $P$ to a more stable crystalline phase of sodalite [20]. The peaks characteristic of quartz can also be seen, indicating that quartz can dissolve slowly but not completely in alkaline medium [21].

SEM micrographs of the fly ash and ZFA are shown in Figure 1. The surface of the synthetic zeolite was rough, and the grain was neatly arranged and had a distinct outline (Figure $1 \mathrm{~b}-\mathrm{d}$ ). The original smooth spherical structure of the fly ash particles (Figure 1a) was completely altered, with a newly formed layered structure of the zeolite crystal, and several dense holes and channels can be observed. This change in surface morphology on the zeolite increases the surface area to some extent, thereby increasing the ion exchange capacity. Zeolite P forms lamellar aggregates and faujasite forms crystal parallel in three dimensions [22]. The SEM images incompletely represent the described crystal structure likely due to the mixed zeolite phase.

As shown in Figure 2, the nitrogen adsorption-desorption isotherms of ZFA show a type IV isotherm with an $\mathrm{H} 3$ hysteresis loop according to the classification of the International Union of Pure and Applied Chemistry (IUPAC). The nitrogen adsorption-desorption isotherms had a larger hysteresis loop at higher relative pressure $\left(\mathrm{P} / \mathrm{P}_{0}\right)$, suggesting the presence of plentiful mesopores in zeolite [23]. 
BET () analysis demonstrated that the specific surface areas of ZFA and raw fly ash were $13.05 \mathrm{~m}^{2} / \mathrm{g}$ and $0.34 \mathrm{~m}^{2} / \mathrm{g}$, respectively. The average pore size and pore volume of ZFA were about $11.19 \mathrm{~nm}$ and $0.04 \mathrm{~cm}^{3} / \mathrm{g}$, respectively. Thus, the synthetic zeolite can effectively adsorb ammonium that can freely enter and exit the channel, which facilitates mass transfer diffusion.
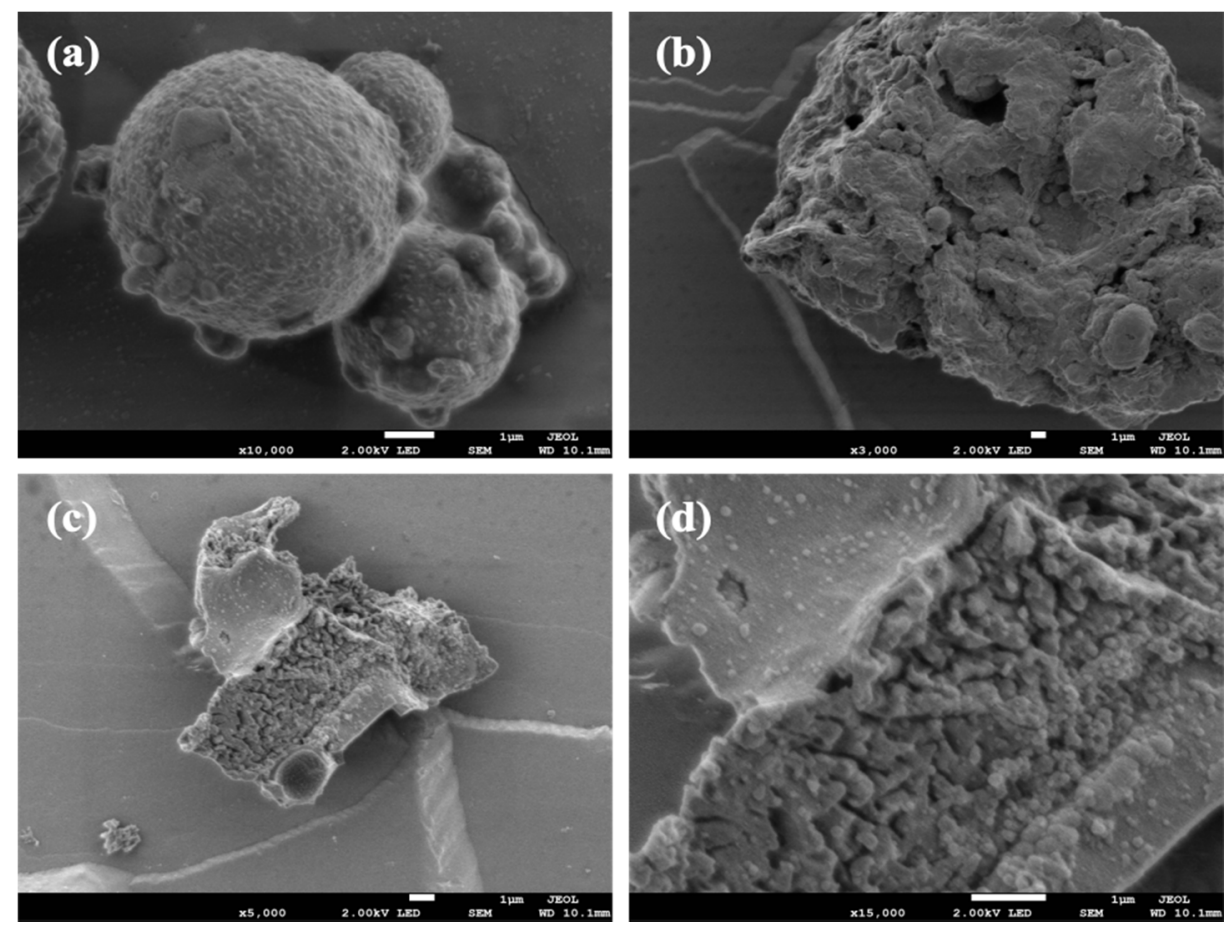

Figure 1. Scanning electron microscopy (SEM) of coal fly ash and synthetic zeolite: (a) coal fly ash; (b-d) synthetic zeolite.

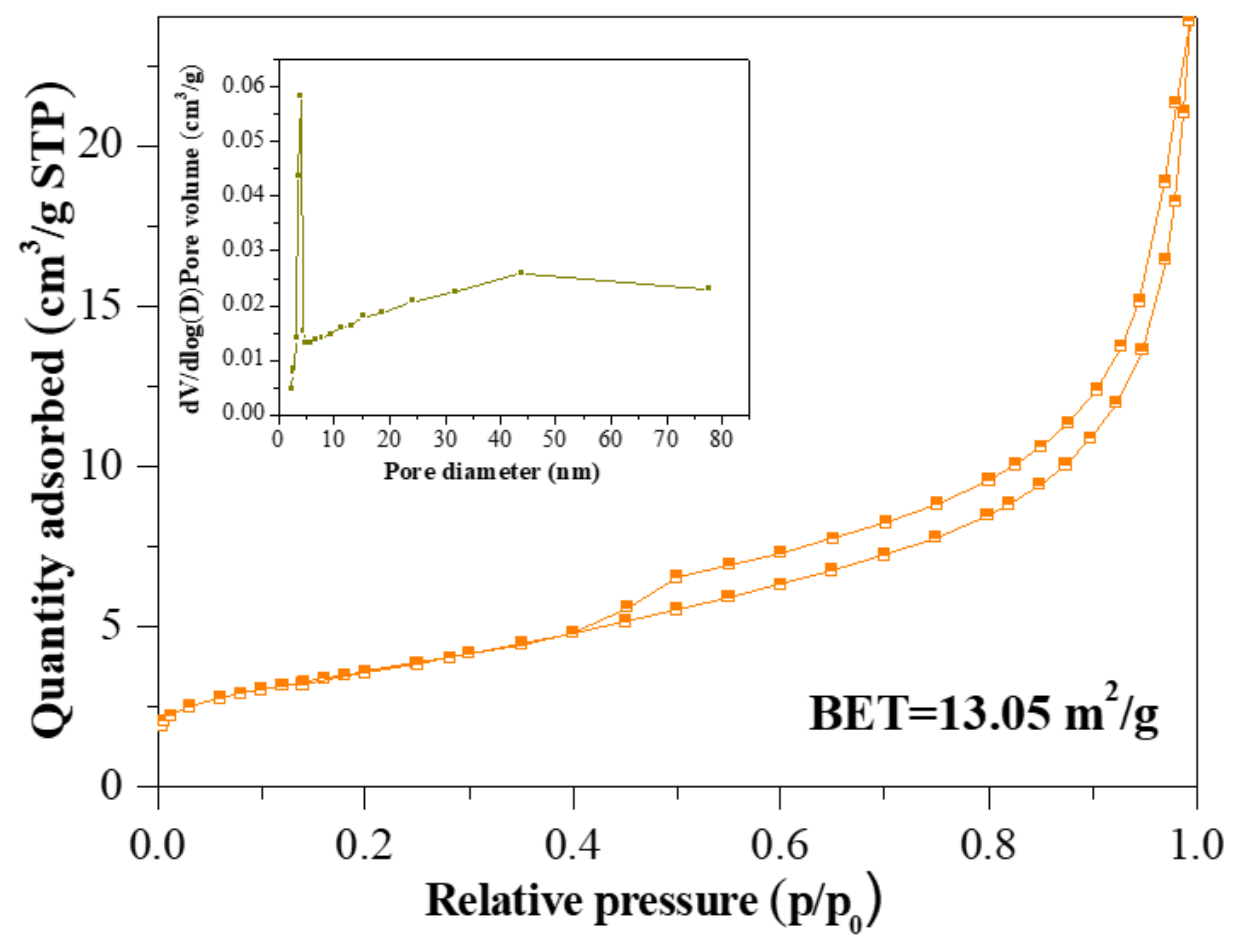

Figure 2. Nitrogen adsorption-desorption isotherms of the synthetic zeolite. BET: Brunauer-EmmettTeller technique. 
The FTIR spectra of ZFA in the wavenumber region from 4000 to $400 \mathrm{~cm}^{-1}$ are shown in Figure S2. The band at $468.70 \mathrm{~cm}^{-1}$ corresponded to the Si-O or Al-O flexural vibration, and the $669.30 \mathrm{~cm}^{-1}$ was assigned to the stretching vibration of the tetrahedral structure [13]. The strong absorption peak at $1033.34 \mathrm{~cm}^{-1}$ should belong to the Si-O-Si skeletal vibration [24]. The bending and stretching vibration peaks of $\mathrm{H}-\mathrm{OH}$ appeared at $1635 \mathrm{~cm}^{-1}$ and $3469 \mathrm{~cm}^{-1}$ [25].

\subsection{Pre-Treatment and Synthetic Parameters}

The ammonium adsorption efficiencies of zeolites synthesized from two pretreated fly ashes are shown in Figure 3. The ammonium removal percentages using zeolite synthesized by deionized water and hydrochloric acid fly ash were $18 \%$ and $75 \%$, respectively. This indicated that water-washing pretreatment for fly ash has a small effect on the ammonium removal, but pickling is effective in the treatment of ammonium. The study reported that some acid soluble impurities can be removed and the activated zeolite has a higher ammonium adsorption capacity [26]. Therefore, acid pickling for fly ash is beneficial to promote the adsorption of ammonium ions in ZFA.

As shown in Figure 4, the synthetic parameters of ZFA have an important effect on ammonium adsorption. As the synthetic time increases, the ammonium removal efficiency of ZFA also increases. This is probably because the crystallization time has a significant impact on the crystal shape and crystallinity of zeolite (Figure 4a). This phenomenon illustrates that the zeolite structure might be unstable when the crystallization time was less than $48 \mathrm{~h}$, but too much time could result in hybrid crystals due to the secondary nucleation [12]. The potential highest ammonium removal efficiency of $83.19 \%$ for zeolite was observed at the synthetic temperature of $100{ }^{\circ} \mathrm{C}$ (Figure $4 \mathrm{~b}$ ). High temperatures may cause the material to clump, while lower temperatures can inhibit or slow crystallization [20]. On increasing the liquid-solid ratio in zeolite synthesis, there was an obvious rising trend of ammonium removal; however, as the liquid-solid ratio exceeded 8, the effect on ammonium adsorption actually became negative (Figure 4c). A lower liquid-solid ratio promotes the dissolution of components, but also allows for the formation of hybrid crystals and results in a higher synthesis cost. Given the economic considerations regarding the material preparation process, the suitable hydrothermal treatment time, temperature, and the liquid-solid ratio were determined to be $48 \mathrm{~h}, 95^{\circ} \mathrm{C}$, and $6 \mathrm{~mL} / \mathrm{g}$, respectively.

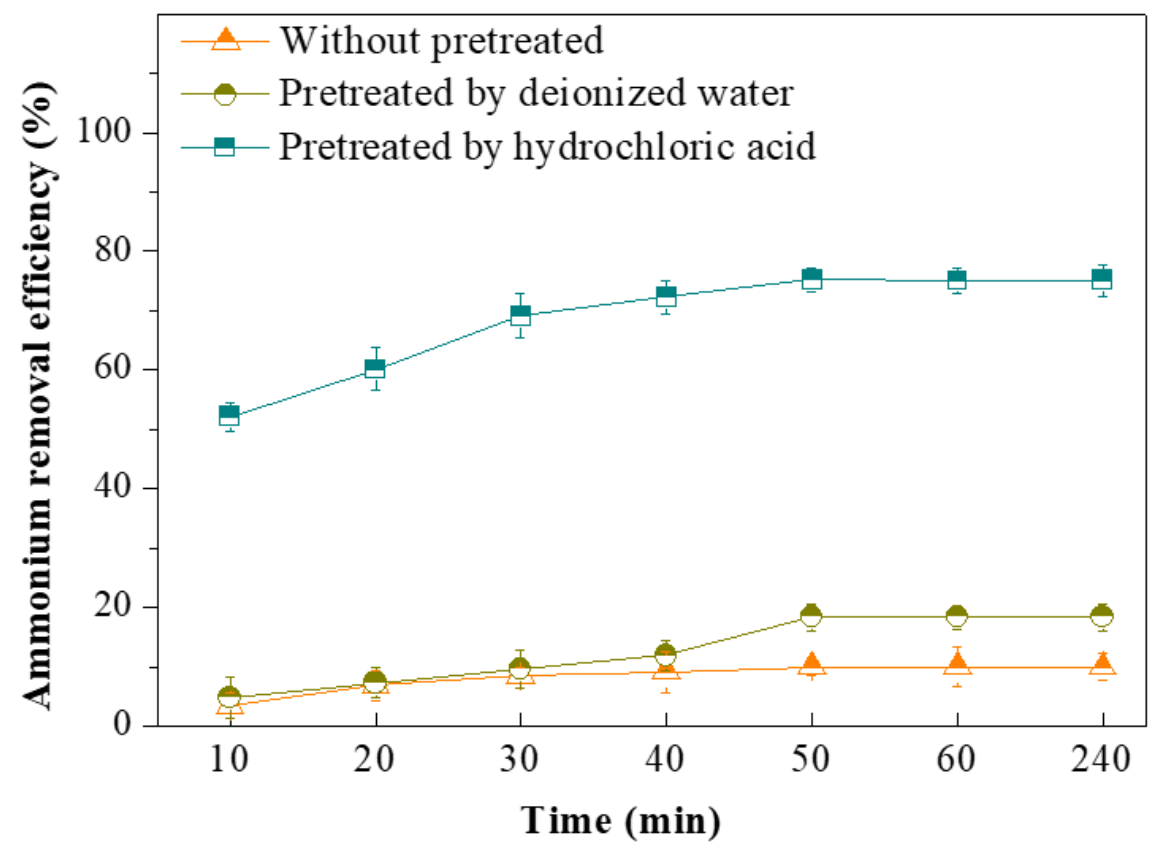

Figure 3. The pretreatment methods on ammonium removal by the synthetic zeolite $(\mathrm{C} 0=100 \mathrm{mg} / \mathrm{L}$; adsorbent dosage $=10 \mathrm{~g} / \mathrm{L} ; \mathrm{pH}=7.0 ; \mathrm{T}=25^{\circ} \mathrm{C}$ ). 

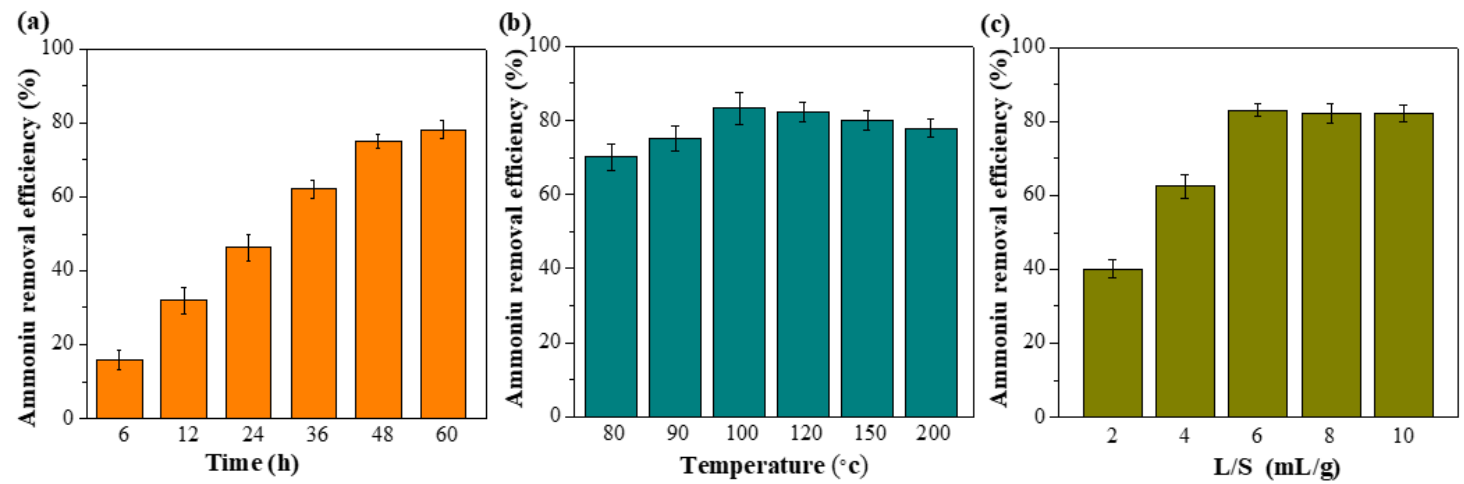

Figure 4. Effect of the (a) reaction time; (b) temperature; and (c) $\mathrm{L} / \mathrm{S}(\mathrm{NaOH}(\mathrm{aq}) / \mathrm{fly}$ ash) on ammonium removal by the synthetic zeolite $\left(\mathrm{C} 0=100 \mathrm{mg} / \mathrm{L}\right.$; adsorbent dosage $\left.=10 \mathrm{~g} / \mathrm{L} ; \mathrm{pH}=7.0 ; \mathrm{T}=25^{\circ} \mathrm{C}\right)$.

\subsection{Parameters Affecting Ammonium Adsorption}

\subsubsection{Effect of $\mathrm{pH}$}

As shown in Figure 5a, the initial $\mathrm{pH}$ had a significant effect on the amount of ammonium adsorbed by the ZFA. The ammonium adsorption capacity exhibits a rising trend along with the $\mathrm{pH}$ increases from 2 to 7 , probably because $\mathrm{pH}$ affects the forms of ammonium in solution [5]. When $\mathrm{pH}<7$, the ion exchange plays a leading role in the adsorption process because most of the ammonium exists in ionized form [27]. The highest ammonium adsorption efficiency increased from $40.3 \%$ to $100.0 \%$ when the initial concentration increased from $20 \mathrm{mg} / \mathrm{L}$ to $500 \mathrm{mg} / \mathrm{L}$ at pH 7.0. However, the ammonium removal efficiency was reduced with the increase of $\mathrm{pH}$; that could be due to the fewer ammonia ions that exist in alkaline environments, and free ammonia cannot exert a concerted effect of ion exchanges with zeolites [28]. At any rate, the results showed that the molecular adsorption is a secondary position for ammonium adsorption by ZFA under neutral $\mathrm{pH}$ conditions.

\subsubsection{Effect of Adsorbent Dosage}

The adsorption equilibrium between adsorbent and ammonium is controlled by the adsorbent dosage. The effect of the ZFA dosage on ammonium removal efficiency is shown in Figure $5 \mathrm{~b}$. An adsorbent dosage of $10 \mathrm{~g} / \mathrm{L}$ was able to adsorb all of the ammonium in wastewater with an initial concentration of $20 \mathrm{mg} / \mathrm{L}$. Given an initial ammonium concentration of $500 \mathrm{mg} / \mathrm{L}$, the removal efficiency increased from $26.3 \%$ to $70.2 \%$ when the ZFA dosage increased from 5 to $60 \mathrm{~g} / \mathrm{L}$. The removal efficiency of ammonium by zeolite increased with increasing adsorbent dosage, which can be ascribed to an increase in the surface area of the adsorbent and the number of active surface sites [29]. The adsorption reached equilibrium when the dosages reached a certain value, which may be caused by aggregate formation or particle precipitation at a high liquid-solid ratio [30]. After the adsorbent dosage reaches the plateau point, the increased adsorption capacity can be disregarded, as the number of unsaturated zeolite ion exchange sites is reduced by the high adsorbent dosage. Therefore, the adsorbent total surface decreased and the length of the diffusion path increased. This influence decreased with a decreasing $\mathrm{NH}_{4}{ }^{+}$concentration per unit mass of adsorbent.

\subsubsection{Effect of Coexisting Ions}

Swine wastewater usually includes some additional substances like $\mathrm{Na}^{+}$and $\mathrm{Ca}^{2+}$, which may reduce the uptake of ammonium using zeolite [29]. Therefore, the influence of $\mathrm{Na}^{+}, \mathrm{Ca}^{2+}, \mathrm{K}^{+}$, and $\mathrm{Mg}^{2+}$ on the ammonium adsorption by the ZFA was studied (Figure 5c). When the initial ammonium concentration was $100 \mathrm{mg} / \mathrm{L}$, the removal efficiency was $82.6 \%$ without coexisting ions, and the removal efficiencies were $76.7 \%, 67.8 \%, 65.9 \%$, and $73.6 \%$ in the presence of $\mathrm{Mg}^{2+}, \mathrm{K}^{+}, \mathrm{Ca}^{2+}$, and $\mathrm{Na}^{+}$, respectively. The results show that cations resulted in a decrease in ammonium adsorption capacity, because these ions compete with ammonium for the available ion exchange sites. The removal 
efficiency of ammonium was slightly influenced by $\mathrm{Mg}^{2+}$ and $\mathrm{Na}^{+}$, but significantly by the presence of $\mathrm{Ca}^{2+}$ and $\mathrm{K}^{+}$; this phenomenon is probably correlated with the adsorption affinity of cations. It has lower adsorption affinity for $\mathrm{Mg}^{2+}$ because of the smallest ion radius among these cations, therefore $\mathrm{Mg}^{2+}$ is not easy to exchange on to a zeolite skeleton [31]. The affecting order of ammonium adsorption is $\mathrm{Ca}^{2+}>\mathrm{K}^{+}>\mathrm{Na}^{+}>\mathrm{Mg}^{2+}$, as some previous studies had found [32]. It indicates that the selectivity order of ammonium over other cations on the synthesized zeolite was $\mathrm{Ca}^{2+}>\mathrm{K}^{+}>\mathrm{Na}^{+}>\mathrm{Mg}^{2+}$. However, several researches showed that ion exchange properties may be different among different zeolites $[31,33]$.

(a)

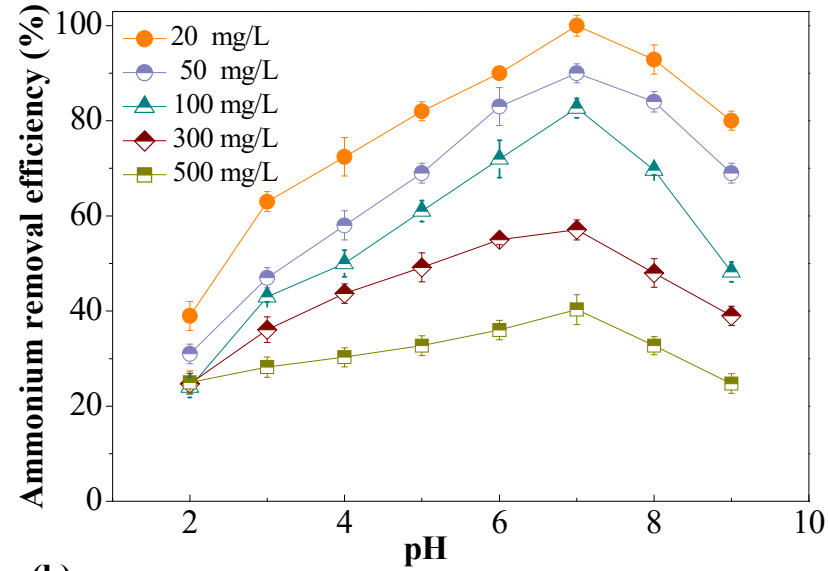

(b)

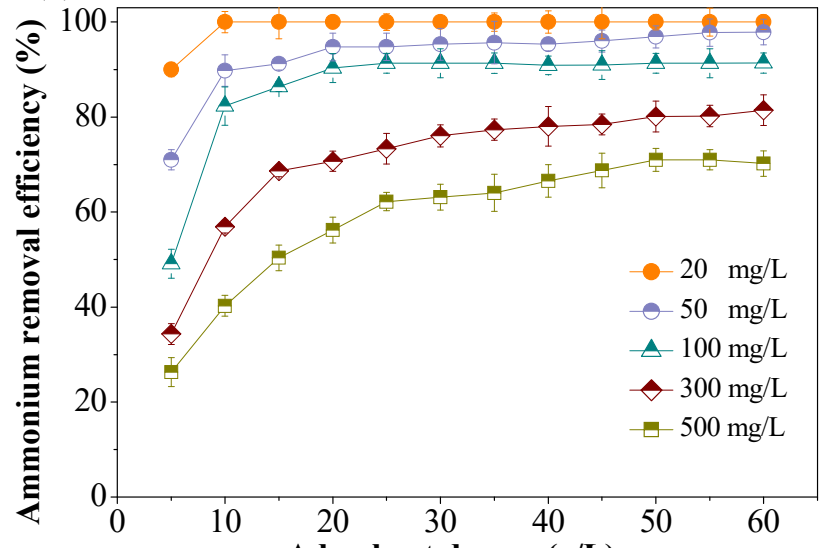

(c)

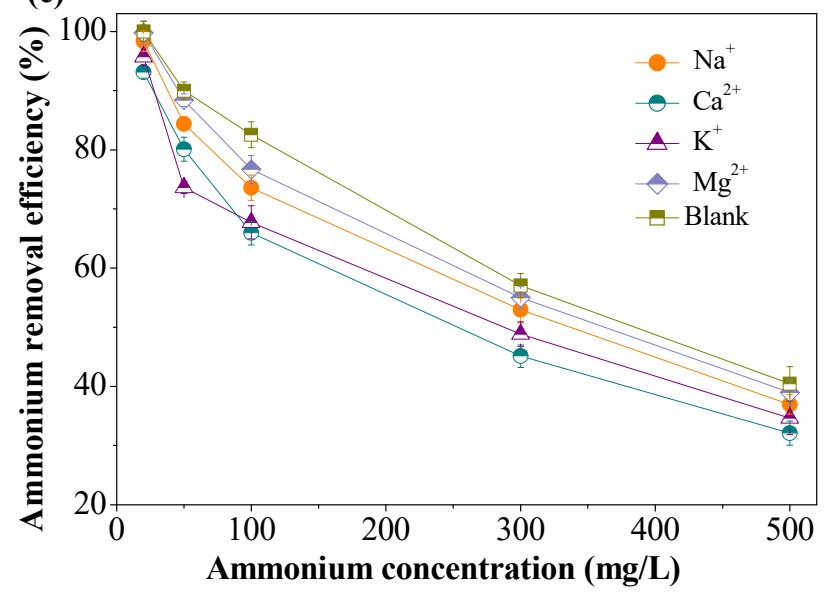

Figure 5. Effect of (a) $\mathrm{pH},(\mathbf{b})$ adsorbent dosage, and (c) cations on the removal of ammonium $\left(\mathrm{T}=25^{\circ} \mathrm{C}\right)$. 


\subsection{Kinetic Analysis}

As Figure $6 \mathrm{a}, \mathrm{b}$ shows, the increase of ammonium adsorption by ZFA was attained in the ambit of $20-500 \mathrm{mg} / \mathrm{L}$ of initial concentrations. With the increment of the beginning concentration of ammonium, the adsorption equilibrium can be easily reached within a short time since the mass driving force was raised. As all the exchangeable $\mathrm{NH}_{4}{ }^{+}$in the solution and cations inside zeolite were reached, the adsorption equilibrium was attained [18]. The ammonium adsorption by ZFA was very rapid from 0-20 $\mathrm{min}$, and surface adsorption (boundary layer diffusion) was predominated during this stage. The adsorption rate was mainly driven by intraparticle diffusion, which means $\mathrm{NH}_{4}{ }^{+}$from the adsorbent exterior surface shifted to the pores from 20-120 $\mathrm{min}$. In this phase, the mass transferred with a greater resistance, and the adsorption rate decreased. Ammonium adsorption on ZFA proceeded fast, probably because of vacant adsorptive sites on the adsorbents [34]. Adsorption equilibrium could be achieved in $120 \mathrm{~min}$. According to Table S1 and Figure $6 \mathrm{c}, \mathrm{d}$, the curve fit of the pseudo-second-order equation $\left(r^{2}=0.999\right)$ is greater than that of the pseudo-first-order equation $\left(r^{2}=0.930\right)$. The pseudo-second-order model indicates that a monolayer adsorption system and the chemical adsorption play the main roles in the process [35]. Other ZFAs produced similar results for ammonia nitrogen adsorption [36,37]. In different initial $\mathrm{NH}_{4}{ }^{+}$concentrations, $\mathrm{t}_{0.5}$ were calculated as $12.01 \mathrm{~min}, 8.83 \mathrm{~min}, 6.75 \mathrm{~min}$, and $5.87 \mathrm{~min}$.
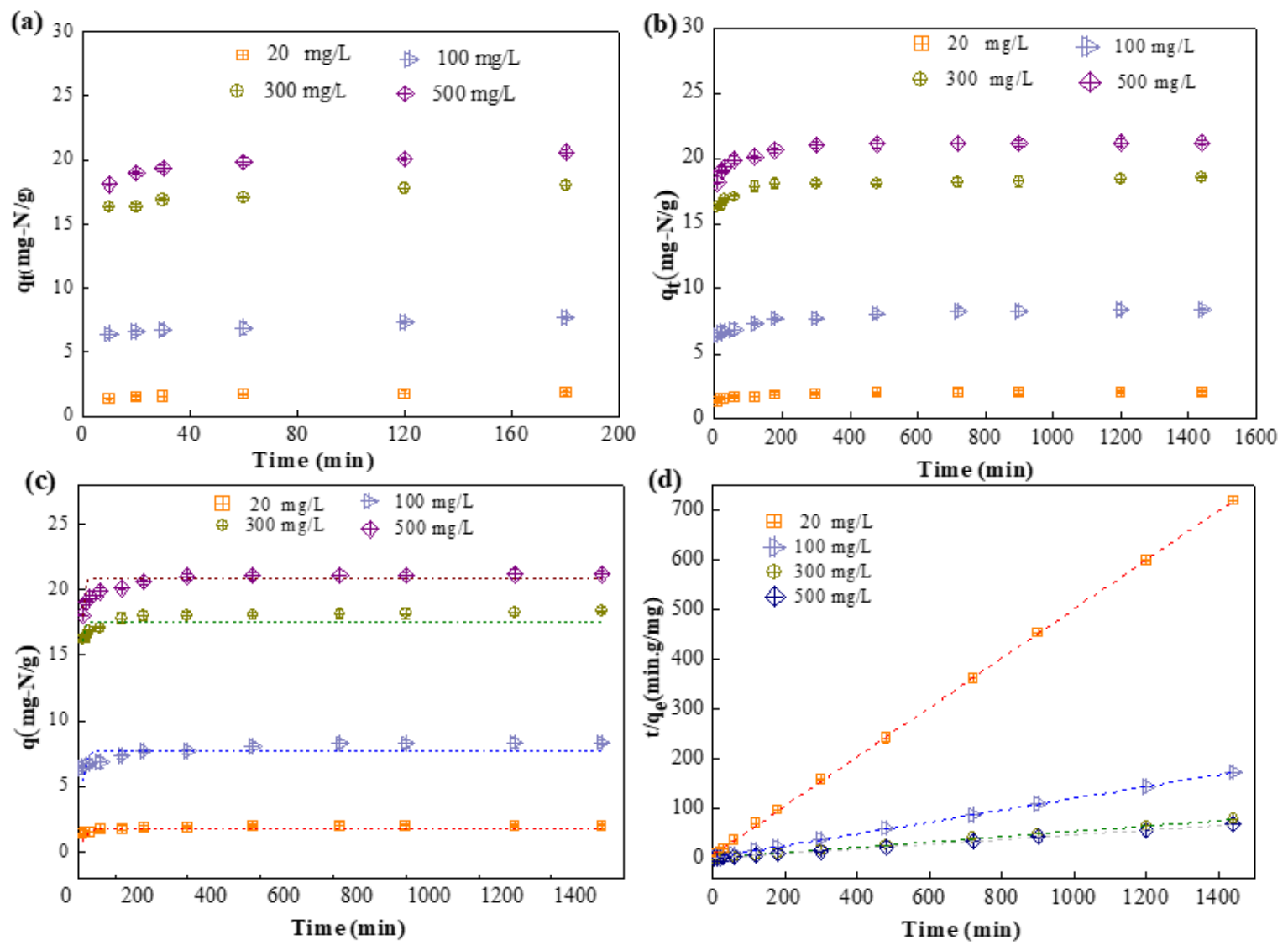

Figure 6. (a,b) Ammonia nitrogen adsorption dynamic by the synthetic zeolite; (c) adsorption kinetics fitted with a pseudo-first-order and (d) a pseudo-second-order model $\left(\mathrm{pH}=7 ; \mathrm{T}=25^{\circ} \mathrm{C}\right)$.

\subsection{Equilibrium Adsorption Isotherms}

An adsorption isotherm describes the interaction between adsorbent surfaces and ammonium ions in solution [38]. The equilibrium adsorption capacity of ZFA for ammonium was measured at three different temperatures $(288,298$, and $308 \mathrm{~K})$. The results of the adsorption isotherm analysis at $298 \mathrm{~K}$ are shown in Figure S3, and the parameters at different temperatures are listed in the Table 3. 
In the model tested on the obtained experimental data, the fitting coefficients $\left(\mathrm{r}^{2}\right)$ of the Langmuir and Freundlich models were 0.96 and 0.95 , respectively, and the maximal adsorption capacity was $32.16 \mathrm{mg} / \mathrm{g}$. It is worth mentioning that the ammonium adsorption capacity of the ZFA in the study is greater than some ZFAs and natural zeolites in previous research (Table S2). In this work, the data fits both the Langmuir and Freundlich models well, indicating that the homogeneous and heterogeneous adsorptions coexist [36]. Under different initial concentration conditions, the dimensionless constant of $R_{L}$ in the Langmuir linear model was between 0 and 1 , which is within the preferred range for adsorption, indicating that the adsorption process is favorable [39].

Table 3. Isotherm parameters for ammonium adsorption onto the synthetic zeolite.

\begin{tabular}{ccccc}
\hline \multirow{2}{*}{ Models } & Parameters & \multicolumn{3}{c}{ Temperature $\left({ }^{\circ} \mathbf{C}\right)$} \\
\cline { 3 - 5 } & & $\mathbf{1 5}$ & $\mathbf{2 5}$ & $\mathbf{3 5}$ \\
\hline \multirow{3}{*}{ Langmuir } & $q_{m}(\mathrm{mg} / \mathrm{g})$ & 33.39 & 32.16 & 31.68 \\
& $k_{l}$ & 0.0079 & 0.0063 & 0.0055 \\
& $r^{2}$ & 0.95 & 0.96 & 0.95 \\
Freundlich & $\left.k_{f}(\mathrm{mg} / \mathrm{g}) /(\mathrm{mg} / \mathrm{L})^{\mathrm{n}}\right)$ & 6.77 & 5.32 & 4.73 \\
& $n$ & 4.68 & 4.17 & 3.97 \\
& $r^{2}$ & 0.95 & 0.95 & 0.93 \\
\hline
\end{tabular}

\subsection{Thermodynamics}

The thermodynamics parameters, such as enthalpy $\left(\Delta \mathrm{H}^{\circ}\right)$, entropy $\left(\Delta \mathrm{S}^{\circ}\right)$, and Gibbs energy $\left(\Delta \mathrm{G}^{\circ}\right)$ for the adsorption of ammonium on ZFA were calculated by Gibbs and Van 't Hoff equations (in the Supplementary material) according to the results for ammonium adsorption onto ZFA at different temperatures. The negative values of $\Delta \mathrm{G}^{\circ}(-2.13,-1.42$, and $-0.70 \mathrm{~kJ} / \mathrm{mol}$ at 288,298 , and $308 \mathrm{~K}$, respectively) in Table 4 indicated that the ammonium adsorption process is feasible and spontaneous, without inputting energy to the system. The change in free energy for physical adsorption was between 0 and $-20 \mathrm{~kJ} / \mathrm{mol}$, therefore the ammonium exchange has physical characteristics [40]. The $\Delta \mathrm{H}^{\circ}$ was negative $(-22.72 \mathrm{~kJ} / \mathrm{mol})$, hence the ammonium removal process is exothermic. This supports the previous result that the adsorption was not suitable under the increasing temperature conditions. A similar trend was also observed with some adsorbents, including natural zeolites [30], synthesized zeolite-Y [41], and zeolite-P1 [36]. It might be that the rising temperature intensifies the instability of ammonium to get away from the solid phase to the liquid phase, which could reduce ammonium sorption capacity. In addition, the adsorption site could be more active at lower temperature [42]. However, increases in the ammonium removal efficiency with increasing temperature have been reported for some other adsorbents [6,29]. Therefore, the effect of temperature on the ammonium adsorption depends on the adsorbents and experimental conditions. The negative value of $\Delta S^{\circ}$ shows that the randomness decreases with the removal of ammonium by the ZFA.

Table 4. Thermodynamic parameters for ammonium adsorption on the synthetic zeolite.

\begin{tabular}{cccc}
\hline Temperature (K) & $\Delta G^{\circ}(\mathbf{k J} / \mathbf{m o l})$ & $\Delta \boldsymbol{H}^{\circ}(\mathbf{k J} / \mathbf{m o l})$ & $\Delta \boldsymbol{S}^{\circ}(\mathrm{kJ} / \mathrm{mol} / \mathrm{K})$ \\
\hline 288 & -2.13 & & \\
298 & -1.42 & -22.72 & -0.071 \\
308 & -0.70 & & \\
\hline
\end{tabular}

\subsection{Adsorption Mechanism}

The removal function is based on the adsorption of zeolites for nonionic ammonia and on the ion exchange of zeolite with ionic ammonia, because zeolite can provide sorption sites with exchangeable cations for $\mathrm{NH}_{4}{ }^{+}$and porosity for free ammonia [43]. The form of ammonia existing in solutions is determined by $\mathrm{pH}$, temperature, and others [44]. The free ammonia is prone to be adsorbed in the 
channel of zeolite in the form of physical adsorption. The internal structure of zeolite has a pyramid (tetrahedron) unit and $\mathrm{Si}^{4+}$ was substituted by $\mathrm{Al}^{3+}$ in the skeletal structure so it has a negative charge [45]. According to the conservation of charge, the negative charge is balanced by cations with positive charge $\left(\mathrm{A}^{\mathrm{n}+}\right.$, such as sodium and calcium ion) on the zeolite's surface, which bind to the zeolite with faint electrostatic action and then have a strong ion exchange capacity for other surrounding cations in a solution [46]. It generally exhibits a high selectivity for $\mathrm{NH}_{4}{ }^{+}$. Equation (4) can be used to describe the process of $\mathrm{NH}_{4}{ }^{+}$and zeolites exchange:

$$
\text { Zeolite }-A^{n+}+n \mathrm{NH}_{4}^{+} \leftrightarrow \text { Zeolite }-n \mathrm{NH}_{4}^{+}+A^{n+}
$$

\subsection{Removal of Ammonium from Real Swine Wastewater}

Wastewater from pig farms has a very complex composition with high chemical oxygen demand (COD), phosphate and other ions [4]. Presently, there are several technologies to remove nutrients from swine wastewater. However, the research subjects are usually digestion liquid [37], diluent, and low-concentration ammonium wastewater [17,47], but not raw swine wastewater. Additionally, swine wastewater treated with zeolites usually undergoes several treatments (dilution, flocculation, anaerobic lagoons, etc.), which significantly reduce the organic load and nutrients. Therefore, the real removal efficiency may be difficult to evaluate. Our concern is whether the ZFA is having significant removal on raw wastewater with high ammonia concentration, so the swine wastewater used was only treated by solid/liquid separation. The theoretical removal rate of ammonium from swine wastewater was calculated according to the linear curve fit shown in Figure S4 using different adsorbent dosages, comparing the result with the experimental value (Table 5), and the efficiency of ammonia nitrogen removal from fresh swine wastewater decreased by $0.90-7.24 \%$. Although some coexisting cations showed inhibition on ammonium removal in simulated wastewater, there is no denying that the ZFA has a good efficiency in the removal of high ammonium in swine wastewater.

Table 5. Analysis of ammonium removal in swine wastewater. ${ }^{a}$ Raw swine wastewater; ${ }^{b}$ Effluent from the biochemical unit.

\begin{tabular}{|c|c|c|c|c|c|c|}
\hline Dosage (g/L) & 10 & 20 & 30 & 40 & 50 & 60 \\
\hline Theoretical removal efficiency ${ }^{a}(\%)$ & 24.44 & 46.76 & 55.40 & 60.84 & 64.99 & 70.63 \\
\hline Actual removal efficiency ${ }^{\mathrm{a}}(\%)$ & 21.64 & 42.07 & 51.57 & 59.94 & 60.66 & 64.34 \\
\hline Effluent concentration a ${ }^{a}(\mathrm{mg} / \mathrm{L})$ & 457.62 & 338.31 & 282.83 & 233.95 & 229.75 & 208.25 \\
\hline Theoretical removal efficiency ${ }^{b}(\%)$ & 73.42 & 83.58 & 86.63 & - & - & - \\
\hline Actual removal efficiency $\mathrm{b}(\%)$ & 66.18 & 78.15 & 79.61 & - & - & - \\
\hline Effluent concentration ${ }^{\mathrm{b}}(\mathrm{mg} / \mathrm{L})$ & 63.92 & 41.30 & 38.54 & - & - & - \\
\hline
\end{tabular}

Studies have shown that the average ratio of biochemical oxygen demand (BOD) to nitrogen $(\mathrm{N})$ in primary treatment effluent was 2.7 , which led to insufficient nitrogen removal in secondary treatment [48]. Therefore, it was important to remove ammonium from primary treatment effluent before secondary treatment in order to improve the $\mathrm{BOD} / \mathrm{N}$ ratio. The ammonium adsorption capacities of ZFA in raw swine wastewater and biochemical unit effluent were $6.26-12.76 \mathrm{mg}-\mathrm{N} / \mathrm{g}$ and $5.02-12.63$ $\mathrm{mg}-\mathrm{N} / \mathrm{g}$, respectively (Figure 7). Under the experimental conditions, the appropriate zeolite dosages for raw wastewater and biochemical unit effluent from a pig farm were determined to be $60 \mathrm{~g} / \mathrm{L}$ and 20 $\mathrm{g} / \mathrm{L}$, respectively. The ammonium removal efficiency is greater than $59 \%$ when the adsorbent dosage is greater than $40 \mathrm{~g} / \mathrm{L}$, which can greatly reduce the ammonia nitrogen load of the biochemical unit [49]. In addition, the ZFAs can be used for the effluent from the biochemical unit. For the outflow from the pig farm biochemical unit, when the zeolite dosage was $10 \mathrm{~g} / \mathrm{L}$, the effluent ammonia nitrogen concentration was $63.92 \mathrm{mg} / \mathrm{L}$, which is less than the $\mathrm{NH}_{4}{ }^{+}$concentration $(80 \mathrm{mg} / \mathrm{L})$ in the discharge standard of pollutant for livestock and poultry breeding (GB18596-2001), ensuring that the swine wastewater effluent complies with the relevant standard [6]. As a result, the application of the ZFAs 
makes the swine wastewater treatment practical and usable. Furthermore, the ammonium adsorption by the ZFA achieved the aim of repurposing waste (fly ash) for the control and treatment of other waste, and the product can be used as a nitrogenous fertilizer after adsorption [50].
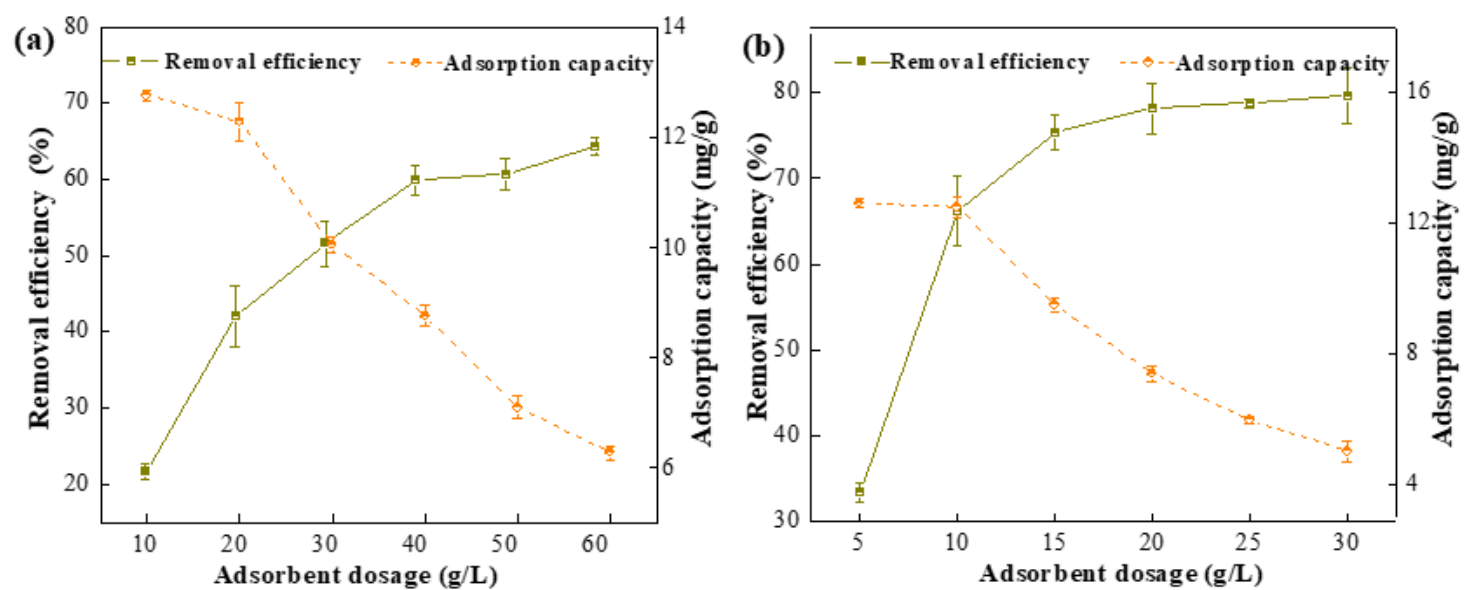

Figure 7. Effect of adsorbent dosage on the ammonium removal from swine wastewater by the synthetic zeolite: (a) raw swine wastewater; (b) effluent from the biochemical unit.

\section{Conclusions}

Zeolite synthesized by pretreated fly ash has good adsorption efficiency for ammonium from swine wastewater in this study. Fitting parameters indicated that a pseudo-second-order kinetic equation fitted well with the adsorption kinetic data and the zeolite rapidly adsorbed ammonium $\left(\mathrm{t}_{0.5}<20 \mathrm{~min}\right)$. The maximum adsorption capacity was estimated as $32.16 \mathrm{mg} / \mathrm{g}$, and both isotherm models, namely Langmuir and Freundlich, fitted well with the adsorption isotherms. The ZFA has a high adsorptive capacity for the removal of high ammonium concentrations from fresh swine wastewater, and it can be used as a fertilizer after adsorption. The synthetic zeolite described in this study has a potential application for ammonium removal, both from raw swine wastewater and pig farm biochemical unit effluent.

Supplementary Materials: The following are available online at http://www.mdpi.com/2071-1050/12/8/3423/s1. Figure S1: XRD of synthetic zeolite $(\mathrm{Y})$ zeolite $\mathrm{Y},(\mathrm{P})$ zeolite $\mathrm{P},(\mathrm{F})$ faujasite, $(\mathrm{Q})$ quartz, Figure S2: FTIR spectrum of synthetic zeolite, Figure S3: Equilibrium isotherm fitted to the Langmuir and the Freundlich models $\left(25^{\circ} \mathrm{C}\right)$, Figure S4: Fitting of ammonium removal efficiency in simulated wastewater, Table S1: The kinetic model parameters for ammonium adsorption of synthetic zeolite, Table S2: Ammonia nitrogen adsorption capacities of various zeolites.

Author Contributions: Conceptualization, X.X.; investigation, H.T. and C.L.; methodology, H.T. and B.W.; writing - original draft, H.T. and C.L.; writing-review and editing, X.X., B.W. and D.S. All authors have read and agreed to the published version of the manuscript.

Funding: This work was supported by the National Key R\&D Program of China under Grant No. 2018YFD1100501.

Conflicts of Interest: The authors declare no conflict of interest.

\section{References}

1. Ye, Z.-L.; Ghyselbrecht, K.; Monballiu, A.; Pinoy, L.; Meesschaert, B. Fractionating various nutrient ions for resource recovery from swine wastewater using simultaneous anionic and cationic selective-electrodialysis. Water Res. 2019, 160, 424-434. [CrossRef] [PubMed]

2. Vadivelu, V.M.; Keller, J.; Yuan, Z. Effect of free ammonia and free nitrous acid concentration on the anabolic and catabolic processes of an enriched Nitrosomonas culture. Biotechnol. Bioeng. 2006, 95, 830-839. [CrossRef] [PubMed] 
3. Meng, J.; Li, J.; He, J.; Li, J.; Deng, K.; Nan, J. Nutrient removal from high ammonium swine wastewater in upflow microaerobic biofilm reactor suffered high hydraulic load. J. Environ. Manag. 2019, 233, 69-75. [CrossRef] [PubMed]

4. Han, Z.; Dong, J.; Shen, Z.; Mou, R.; Zhou, Y.; Chen, X.; Fu, X.; Yang, C. Nitrogen removal of anaerobically digested swine wastewater by pilot-scale tidal flow constructed wetland based on in-situ biological regeneration of zeolite. Chemosphere 2019, 217, 364-373. [CrossRef] [PubMed]

5. Fan, R.; Chen, C.-L.; Lin, J.-Y.; Tzeng, J.-H.; Huang, C.-P.; Dong, C.; Huang, C.P. Adsorption characteristics of ammonium ion onto hydrous biochars in dilute aqueous solutions. Bioresour. Technol. 2019, 272, 465-472. [CrossRef]

6. Zhang, P.; Zeng, X.; Wen, X.; Yang, C.; Ouyang, S.; Li, P.; Gu, Z.; Wu, D.; Frost, R.L. Insights into efficient removal and mechanism for ammonium from aqueous solution on tricalcium aluminate. Chem. Eng. J. 2019, 366, 11-20. [CrossRef]

7. Li, R.; Wang, J.J.; Zhou, B.; Zhang, Z.; Liu, S.; Lei, S.; Xiao, R. Simultaneous capture removal of phosphate, ammonium and organic substances by $\mathrm{MgO}$ impregnated biochar and its potential use in swine wastewater treatment. J. Clean. Prod. 2017, 147, 96-107. [CrossRef]

8. Song, H.; Wang, J.; Garg, A.; Lin, X.; Zheng, Q.; Sharma, S. Potential of Novel Biochars Produced from Invasive Aquatic Species Outside Food Chain in Removing Ammonium Nitrogen: Comparison with Conventional Biochars and Clinoptilolite. Sustainability 2019, 11, 7136. [CrossRef]

9. Mitrogiannis, D.; Psychoyou, M.; Koukouzas, N.; Tsoukalas, N.; Palles, D.; Kamitsos, E.; Pantazidis, A.; Oikonomou, G.; Baziotis, I. Phosphate recovery from real fresh urine by $\mathrm{Ca}(\mathrm{OH})(2)$ treated natural zeolite. Chem. Eng. J. 2018, 347, 618-630. [CrossRef]

10. Lee, Y.-R.; Soe, J.T.; Zhang, S.; Ahn, J.-W.; Park, M.B.; Ahn, W.-S. Synthesis of nanoporous materials via recycling coal fly ash and other solid wastes: A mini review. Chem. Eng. J. 2017, 317, 821-843. [CrossRef]

11. Juan, R.; Hernandez, S.; Andres, J.M.; Ruiz, C. Ion exchange uptake of ammonium in wastewater from a Sewage Treatment Plant by zeolitic materials from fly ash. J. Hazard. Mater. 2009, 161, 781-786. [CrossRef] [PubMed]

12. He, W.; Gong, H.; Fang, K.; Peng, F.; Wang, K. Revealing the effect of preparation parameters on zeolite adsorption performance for low and medium concentrations of ammonium. J. Environ. Sci. 2019, 85, 177-188. [CrossRef] [PubMed]

13. Sivalingam, S.; Sen, S. Optimization of synthesis parameters and characterization of coal fly ash derived microporous zeolite X. Appl. Surf. Sci. 2018, 455, 903-910. [CrossRef]

14. Joshi, P. Clean \& Sustainable process for Zeolite Synthesis: Effect of Acidic Pretreatment and Double Fusion on the Characteristics. Mater. Today Proc. 2017, 4, 10484-10488.

15. Chen, X.; Guo, Y.; Cheng, F.; Song, H.; Zheng, N.; Wang, X. Application of Modified Coal Fly Ash as an Absorbent for Ammonia-Nitrogen Wastewater Treatment. In Advances in Environmental Science and Engineering, Pts 1-6; Iranpour, R., Zhao, J., Wang, A., Yang, F.L., Li, X., Eds.; Trans Tech Publications Ltd.: Zurich, Switzerland, 2012; pp. 2380-2384.

16. He, H.; Xu, S.; Han, R.; Wang, Q. Nutrient sequestration from wastewater by using zeolite Na-P1 synthesized from coal fly ash. Environ. Technol. 2017, 38, 1022-1029. [CrossRef]

17. Cardoso, A.M.; Horn, M.B.; Ferret, L.S.; Azevedo, C.M.N.; Pires, M. Integrated synthesis of zeolites 4A and Na-P1 using coal fly ash for application in the formulation of detergents and swine wastewater treatment. J. Hazard. Mater. 2015, 287, 69-77. [CrossRef]

18. Zhang, M.; Zhang, H.; Xu, D.; Han, L.; Niu, D.; Zhang, L.; Wu, W.; Tian, B. Ammonium removal from aqueous solution by zeolites synthesized from low-calcium and high-calcium fly ashes. Desalination 2011, 277, 46-53. [CrossRef]

19. Garcia, G.; Cardenas, E.; Cabrera, S.; Hedlund, J.; Mouzon, J. Synthesis of zeolite Y from diatomite as silica source. Microporous Mesoporous Mater. 2016, 219, 29-37. [CrossRef]

20. Liu, Y.; Luo, Q.; Wang, G.; Li, X.; Na, P. Synthesis and characterization of zeolite from coal fly ash. Mater. Res. Express 2018, 5. [CrossRef]

21. Cardoso, A.M.; Paprocki, A.; Ferret, L.S.; Azevedo, C.M.N.; Pires, M. Synthesis of zeolite Na-P1 under mild conditions using Brazilian coal fly ash and its application in wastewater treatment. Fuel 2015, 139, 59-67. [CrossRef] 
22. Franus, W.; Wdowin, M.; Franus, M. Synthesis and characterization of zeolites prepared from industrial fly ash. Environ. Monit. Assess. 2014, 186, 5721-5729. [CrossRef] [PubMed]

23. Liu, Y.; Wang, G.; Luo, Q.; Li, X.; Wang, Z. The thermodynamics and kinetics for the removal of copper and nickel ions by the zeolite $Y$ synthesized from fly ash. Mater. Res. Express 2019, 6. [CrossRef]

24. Yao, Y.; Sun, H. A novel silica alumina-based backfill material composed of coal refuse and fly ash. J. Hazard. Mater. 2012, 213, 71-82. [CrossRef] [PubMed]

25. Zhang, Y.; Kang, W.; Han, H.; Wang, H.; Chen, Y.; Gong, X.; Zhai, C.; Song, H. In-situ synthesis of NaP zeolite doped with transition metals using fly ash. J. Am. Ceram. Soc. 2019, 102, 7665-7677. [CrossRef]

26. Juan, R.; Hernandez, S.; Andres, J.M.; Ruiz, C. Synthesis of granular zeolitic materials with high cation exchange capacity from agglomerated coal fly ash. Fuel 2007, 86, 1811-1821. [CrossRef]

27. Zhou, L.; Boyd, C.E. Total ammonia nitrogen removal from aqueous solutions by the natural zeolite, mordenite: A laboratory test and experimental study. Aquaculture 2014, 432, 252-257. [CrossRef]

28. Huang, H.; Xiao, X.; Yan, B.; Yang, L. Ammonium removal from aqueous solutions by using natural Chinese (Chende) zeolite as adsorbent. J. Hazard. Mater. 2010, 175, 247-252. [CrossRef]

29. Kizito, S.; Wu, S.; Kirui, W.K.; Lei, M.; Lu, Q.; Bah, H.; Dong, R. Evaluation of slow pyrolyzed wood and rice husks biochar for adsorption of ammonium nitrogen from piggery manure anaerobic digestate slurry. Sci. Total Environ. 2015, 505, 102-112. [CrossRef]

30. Alshameri, A.; Yan, C.; Al-Ani, Y.; Dawood, A.S.; Ibrahim, A.; Zhou, C.; Wang, H. An investigation into the adsorption removal of ammonium by salt activated Chinese (Hulaodu) natural zeolite: Kinetics, isotherms, and thermodynamics. J. Taiwan Inst. Chem. Eng. 2014, 45, 554-564. [CrossRef]

31. Huang, H.; Xiao, D.; Pang, R.; Han, C.; Ding, L. Simultaneous removal of nutrients from simulated swine wastewater by adsorption of modified zeolite combined with struvite crystallization. Chem. Eng. J. 2014, 256, 431-438. [CrossRef]

32. Weatherley, L.R.; Miladinovic, N.D. Comparison of the ion exchange uptake of ammonium ion onto New Zealand clinoptilolite and mordenite. Water Res. 2004, 38, 4305-4312. [CrossRef] [PubMed]

33. Pan, M.; Zhang, M.; Zou, X.; Zhao, X.; Deng, T.; Chen, T.; Huang, X. The investigation into the adsorption removal of ammonium by natural and modified zeolites: Kinetics, isotherms, and thermodynamics. Water SA 2019, 45, 648-656. [CrossRef]

34. Lin, L.; Lei, Z.; Wang, L.; Liu, X.; Zhang, Y.; Wan, C.; Lee, D.-J.; Tay, J.H. Adsorption mechanisms of high-levels of ammonium onto natural and NaCl-modified zeolites. Sep. Purif. Technol. 2013, 103, 15-20. [CrossRef]

35. Li, Y.; Jin, H.; Liu, W.; Su, H.; Lu, Y.; Li, J. Study on regeneration of waste powder activated carbon through pyrolysis and its adsorption capacity of phosphorus. Sci. Rep. 2018, 8. [CrossRef] [PubMed]

36. Liu, Y.; Yan, C.; Zhao, J.; Zhang, Z.; Wang, H.; Zhou, S.; Wu, L. Synthesis of zeolite P1 from fly ash under solvent-free conditions for ammonium removal from water. J. Clean. Prod. 2018, 202, 11-22. [CrossRef]

37. Li, J.; Zhang, Z.; Khunjar, W.; Zhao, K. Enhanced nutrient sequestration from swine wastewater using zeolite synthesized from fly ash integrated with surface amendment technique. Fuel 2013, 111, 57-65. [CrossRef]

38. Wang, Y.; Lin, F.; Pang, W. Removal of ammonium ions from wastewater using modified zeolites. Fresenius Environ. Bull. 2007, 16, 24-28.

39. Lalley, J.; Han, C.; Mohan, G.R.; Dionysiou, D.D.; Speth, T.F.; Garland, J.; Nadagouda, M.N. Phosphate removal using modified Bayoxide (R) E33 adsorption media. Environ. Sci. Water Res. Technol. 2015, 1, 96-107. [CrossRef]

40. Zheng, H.; Han, L.; Ma, H.; Zheng, Y.; Zhang, H.; Liu, D.; Liang, S. Adsorption characteristics of ammonium ion by zeolite 13X. J. Hazard. Mater. 2008, 158, 577-584. [CrossRef]

41. Zhao, Y.; Zhang, B.; Zhang, Y.; Wang, J.; Liu, J.; Chen, R. Removal of Ammonium from Wastewater by Pure Form Low-Silica Zeolite Y Synthesized tfrom Halloysite Mineral. Sep. Sci. Technol. 2010, 45, 1066-1075. [CrossRef]

42. Zhao, Y.; Zhang, B.; Zhang, X.; Wang, J.; Liu, J.; Chen, R. Preparation of highly ordered cubic NaA zeolite from halloysite mineral for adsorption of ammonium ions. J. Hazard. Mater. 2010, 178, 658-664. [CrossRef] [PubMed]

43. Wijesinghe, D.T.N.; Dassanayake, K.B.; Scales, P.; Sommer, S.G.; Chen, D. Removal of excess nutrients by Australian zeolite during anaerobic digestion of swine manure. J. Environ. Sci. Health Part A 2018, 53, 362-372. [CrossRef] [PubMed] 
44. Guo, J. Adsorption characteristics and mechanisms of high-levels of ammonium from swine wastewater using natural and MgO modified zeolites. Desalin. Water Treat. 2016, 57, 5452-5463. [CrossRef]

45. Jha, V.K.; Hayashi, S. Modification on natural clinoptilolite zeolite for its $\mathrm{NH}_{4}{ }^{+}$retention capacity. J. Hazard. Mater. 2009, 169, 29-35. [CrossRef] [PubMed]

46. Belova, T.P. Adsorption of heavy metal ions $\left(\mathrm{Cu}^{2+}, \mathrm{Ni}^{2+}, \mathrm{Co}^{2+}\right.$ and $\left.\mathrm{Fe}^{2+}\right)$ from aqueous solutions by natural zeolite. Heliyon 2019, 5. [CrossRef]

47. Cao, L.; Wang, J.; Xiang, S.; Huang, Z.; Ruan, R.; Liu, Y. Nutrient removal from digested swine wastewater by combining ammonia stripping with struvite precipitation. Environ. Sci. Pollut. Res. 2019, 26, 6725-6734. [CrossRef]

48. Dote, Y.; Sekito, T.; Ueda, K.; Sakamoto, R.; Suzuki, T.; Sano, S. Removal of ammonia from aqueous solution for swine wastewater with swine manure compost-based char. Water Pract. Technol. 2015, 10, 409-414. [CrossRef]

49. Dong, Y.-B.; Lin, H. Ammonia nitrogen removal from aqueous solution using zeolite modified by microwave-sodium acetate. J. Cent. South Univ. 2016, 23, 1345-1352. [CrossRef]

50. Souza, I.M.S.; Gurgel, G.C.S.; Medeiros, A.M.; Zonta, E.; Ruiz, J.A.C.; Paskocimas, C.A.; Motta, F.V.; Bomio, M.R.D. The use of clinoptilolite as carrier of nitrogened fertilizer with controlled release. J. Environ. Chem. Eng. 2018, 6, 4171-4177. [CrossRef]

(C) 2020 by the authors. Licensee MDPI, Basel, Switzerland. This article is an open access article distributed under the terms and conditions of the Creative Commons Attribution (CC BY) license (http://creativecommons.org/licenses/by/4.0/). 